\title{
Research on Technical Points of Installation and Construction of Mechanical and Electrical Engineering
}

Ze Li ${ }^{1}$, Li Wang ${ }^{2}$, Subin $\mathrm{Li}^{3}$, Xinjing Zhang ${ }^{4}$,Guosen Zhou ${ }^{5}$

${ }^{1}$ China University of Petroleum (East China), Shijiazhuang, Hebei Province, 050100

${ }^{2}$ Hebei University of Technology, Shijiazhuang, Hebei Province, 050100

${ }^{3}$ Hebei University of Technology, Shijiazhuang, Hebei Province, 050100

${ }^{4}$ Henan Polytechnic University, Shijiazhuang, Hebei Province, 050100

${ }^{5}$ Xinyang Normal University, Shijiazhuang, Hebei Province, 050100

\begin{abstract}
With the rapid development of China's overall economy, the construction engineering industry is gradually improving. Architectural engineering is an important environment for people to live, and its quality and safety are directly related to people's life and property. The most important part of the construction project is the mechanical and electrical installation, to realize the cost control of the project is the key point of the project. This article mainly explains the mechanical and electrical installation engineering in building engineering, and introduces the installation and construction technology in mechanical and electrical installation engineering in detail, and analyzes the control difficulties. It provides an important reference for the management of mechanical and electrical installation technology in the future.
\end{abstract}

Keywords: mechanical and electrical engineering; installation; construction technique; research

\section{Introduction}

In the construction engineering, the mechanical and electrical installation engineering is a very important project. The quality of the installation directly affects the later use of the project. In the mechanical and electrical installation, the control of construction technology mainly refers to that under the premise of ensuring the quality of mechanical and electrical installation, the scientific control of manpower and material resources in engineering construction. By scientifically controlling the manpower and material resources used in the construction of the project, the quality of the installation works can be improved. Mechanical and electrical installation engineering is very important in building engineering. Electromechanical installation works run through the whole process of construction. The quality of electromechanical installation has an important influence on the safety, aesthetics and practicability of building engineering. The cost of construction and installation works on the social and economic benefits of the construction project. With the continuous development of our society and economy, science and technology are also improving. Building engineering plays an important role in the construction process, including economic benefits, environmental benefits and human benefits. Therefore, the installation quality control of the mechanical and electrical installation engineering in the construction project has a very important impact on the whole project ${ }^{[1]}$.

Copyright (C) 2018 Ze Li et al.

doi: $10.18686 /$ esta.v5i2

This is an open-access article distributed under the terms of the Creative Commons Attribution Unported License

(http://creativecommons.org/licenses/by-nc/4.0/), which permits unrestricted use, distribution, and reproduction in any medium, provided the original work is properly cited. 


\section{Installation and construction characteristics of mechanical and electrical equipment}

Mechanical and electrical installation engineering in building engineering is a key project to ensure the normal use of buildings. In electromechanical installation, the installation of electromechanical equipment involves a wide range of construction, including industrial and agricultural machinery and electrical equipment. This is related to the construction of fire, electrical, water supply and drainage and other aspects of the content, which is very widely used in the installation and construction of mechanical and electrical engineering. For the installation of mechanical and electrical equipment, from the purchase of the equipment to the installation, debugging, and operation of the equipment, strict management and control are required. In the mechanical and electrical installation engineering, many new technologies and new technologies are involved. These technologies have promoted the rapid development of the whole mechanical and electrical industry. In many large construction projects in China, the construction requirements of mechanical and electrical engineering are also gradually improving. Therefore, installation and construction technology of electromechanical equipment is needed to ensure the smooth completion of mechanical and electrical engineering and provide important support for the construction of construction projects.

\section{Key points of mechanical and electrical engineering installation}

\subsection{Do a good job of preparation}

The installation of mechanical and electrical engineering, which is the same as the construction of the building, needs to be well prepared for the early stage. First of all, we have to have a detailed understanding of the drawings, complete all drawings, clear the problem, and make communications and adjustments, to ensure the accuracy of the drawings, so as to provide a good foundation for the construction. As the implementer of the project, the construction unit needs to have an accurate observation of the drawings, and compare the electromechanical construction drawings with the civil construction drawings, so as to ensure the smooth progress of each process. Secondly, check the annotation and specific details between the floor plan and the distribution system diagram, check the size and specifications of the equipment, strictly carry out the construction according to the relevant provisions and technical standards, ensure the safety of electricity in the process of ${ }^{[2]}$.

\subsection{System debugging technology}

After the installation of electromechanical engineering, we need to debug. The main purpose of debugging is to check the installation quality of various lines and equipment, and ensure that they meet the design requirements and requirements. System debugging is an important link in the smooth operation of mechanical and electrical equipment. In our actual work, the installation of mechanical and electrical equipment needs many aspects, such as dismantling, transportation, reinstallation and so on. In this process, it may be affected by many factors and cannot work normally. After the installation of mechanical and electrical equipment, whether the use of mechanical equipment can be same with the previous working state, it must be maintained through the method of debugging.

\subsection{Technical points for installation of electric box}

The use of the distribution box is generally in the room of the building, and when the distribution box is installed, the actual situation of the construction site should be understood. In the process of mechanical and electrical engineering installation, the installation of the distribution box needs to cooperate with the civil construction, and can be carried out after the ground construction is completed. In order to prevent human touch, the distribution box should be painted in the obvious position. In the process of installation, if you need to be close to the wall, you should leave a certain distance from the bottom of the box with the ground. Because it is a professional electrical equipment, it must be installed by a professional electrician. In the process of installation, the position of the cut should be neatly and accurately. The distribution box cover should be consistent with the wall surface after the distribution box is installed. ${ }^{[3]}$ 


\subsection{Installation of weak power function of machine and equipment}

In the process of building engineering, there will be many different types of weak current function system. Usually, it includes internal information communication system and monitoring management system. Before the installation of the weak power system, the related inspection of the mechanical equipment will be carried out. Which can guarantee the debugging work of the system can be carried out smoothly after connecting the circuit. In addition, the testing of the machine is also more accurate. The installation of the weak power system is usually completed after the completion of the construction project.

\subsection{Installation and deployment technology of distribution box}

In the installation of mechanical and electrical engineering, the corresponding type of distribution box should be used, and the function of the distribution box in different construction places is different. Therefore, the selection of the distribution box in the construction enterprise should be based on the design requirements and configuration of the project. The adjustment plan and the change plan should be worked out in time and effectively for some emergencies in the installation project. Ensure the quality and performance of the construction project. So, before choosing the distribution box, it is necessary to install the waterproof equipment to ensure the safety of its use.

\section{Key points for the quality control and management of electrical and electrical installation engineering}

\subsection{Strengthening the management of the material and equipment of the building mechanical and electrical installation engineering}

In the process of mechanical and electrical engineering installation, there is a close connection between the use of materials and equipment, and attention should be paid to it. First of all, a strict system of electromechanical installation management should be established. The technical requirements of the mechanical and electrical installation engineering are relatively high. The raw materials used during the construction must meet the needs of the engineering. In accordance with the actual requirements of the project, the material is tendering. In this process, the professional technicians are required to track the material problems.

In addition, we should be careful in choosing suppliers. A good supplier can achieve all aspects of material and equipment services, which can greatly reduce the cost of procurement. The relevant management departments of the state need to publicize them, assist the construction enterprises to select and understand suppliers, so that the cost of materials can be greatly saved, so as to realize the cost control of engineering. ${ }^{[4]}$

\subsection{Do a good job of acceptance of reserved and concealed work}

In the process of the installation of the mechanical and electrical equipment in the building, the construction environment is general, and the difficulty of the construction is also different. Before the installation of mechanical and electrical equipment, it is necessary to do a good job in the use and inspection of the reserved and concealed projects. In the process of construction, the staff must strictly record and check the hidden works in construction engineering according to the requirements of the drawings and specifications. For example, in the process of concrete pouring, the staff needs to reserve a certain hole in the process of construction and examine the holes. This can effectively avoid the displacement of the hole, control the time of the die dismantling, and improve the strength of the concrete.

\subsection{Be sure to implement the standard of design quality management}

In the quality management of the mechanical and electrical engineering of the building engineering, the fine management should be carried out, and the quality of the project can be ensured through strict management. Therefore, in the process of installation and commissioning of the equipment, the design quality of the installation project should be controlled according to the relevant standards and specifications of the installation technology. At the same time, we should improve the professional skill level and comprehensive quality ability of the designer, and improve the 
designer's management consciousness of quality and safety. At the same time, the design work should be carried out according to the relevant national design standards to ensure the quality of the installation project.

\subsection{Attach great importance to key management points related to construction technology}

In addition to the improvement of the quality system, the installation of mechanical and electrical engineering needs strict quality management. Suitable construction technology is chosen according to the characteristics of the project. In the stage of installation and construction, it is necessary to make a precise analysis of the project according to the actual situation of the project, and according to the results of the analysis, the new measures for the construction of the project should be formulated. From the actual operation, in the process of installation technology standards implementation, construction enterprises need to develop targeted files, if there are any questions or problems, you need to install the enterprise production and timely and equipment for effective communication and feedback, so as to ensure that the construction technology of construction workers can meet the installation requirements of the equipment, improve the installation quality of mechanical and electrical engineering.

\subsection{Strengthening the quality management of Engineering}

In engineering construction, if there is engineering quality problem, it may be related to the stoppage or rework of the project, which will cause serious impact on the cost control of the project. At present, many uncompleted residential building projects in China are obvious examples. In engineering construction, these projects do not control the quality and safety of the projects effectively, and finally cause the project to fail to be qualified, and will not be put into use, causing serious economic losses. Therefore, in the installation process of electromechanical engineering, we must strictly manage the quality of installation engineering, find out the existing problems in time, deal with the problems, avoid serious problems, and cause serious safety risks. In this way, during the process of engineering installation, construction units should constantly improve the technology of construction, and establish a perfect engineering quality acceptance management system, so as to avoid the problems of engineering quality and cause economic losses to the project.

\subsection{Strengthen the construction of the construction team}

For the installation of electromechanical engineering, the most important factor is the professional skill level of the construction operator, which has important influence on the installation quality of building appliance engineering. As a manager of an enterprise, it is necessary to improve the comprehensive quality of the installation technicians of electromechanical engineering. Based on the actual situation of the project, regular training and corresponding re education for staff are carried out, which can improve the professional skills of the staff and the corresponding ideological and moral quality. Ensure the successful implementation and development of the project. ${ }^{[5]}$

\subsection{Key points for safety inspection in construction site}

The quality management and inspection of the construction site during the installation process of the construction project has an important influence on the quality of the mechanical and electrical installation. During the installation of the construction site, we need to pay attention to the following aspects: first, to improve the safety inspection, for the safety of construction technicians, we should advocate safe and civilized construction, do well the corresponding precautions, and reduce the problems of safety accidents in the construction site. Second, make strict management of the process of construction work and real-time supervision of the installation of personnel and equipment, control the operation of the process. In the actual installation work of electromechanical engineering, we must make mandatory formulation of the corresponding operation rules and standards, and ensure that every process of installation is up to the qualified standard. Third, we must supervise and control the construction technology during the installation process. After the installation work, we need professional technicians to check the quality. In the process of inspection, if there are quality defects or problems, we need to inform the construction operators to solve the problems effectively, reduce hidden dangers in later construction, and improve the safety and quality of electrical and mechanical engineering. 


\section{Conclusion}

To sum up, the mechanical and electrical engineering of our country is facing great challenges at present. With the emergence of the intelligent construction team, the installation technology becomes more and more complex. In this case, it has a certain advantage for the development of mechanical and electrical engineering. However, the mechanical and electrical installation technology involves a lot of content, such as electric, air conditioning, intelligent system, etc. Therefore, the application of technology should be rationally selected in the installation of mechanical and electrical engineering to ensure that the installation of mechanical and electrical engineering can meet the requirements of use. In the current environment, the installation of mechanical and electrical engineering in China is not ideal, and there are many factors that affect it. Therefore, construction enterprises must make reasonable solutions combined with on-site, so as to ensure the smooth operation of the installation.

\section{References}

1. Yongkun Zhong. Discussion on construction safety management and quality control in mechanical and electrical installation engineering [J]. Southern agricultural machinery 2017, 48 (2): 166+174..

2. Bohuai Wang, Jingwei Guan, Fei Sun. Analysis of electrical construction quality control strategy of electromechanical installation engineering [J]. Southern agricultural machinery, 2017,48 (4): 186.

3. Jingkai Zhao. The key working procedure of electrical construction in mechanical and electrical installation engineering control [J]. Engineering technology research, 2017 (5): 80-81.

4. Min Xiong. Control and management measures for key process of electrical construction in electrical and electrical installation engineering [J]. Engineering Technology: Citation version, 2016 (4):123-124.

5. Jie Luan. Analysis of process control and management in electrical construction of mechanical and electrical installation engineering [J]. Urban construction theory research: Electronic version, 2015, 5 (36). 